\title{
УРБОГЕОСИСТЕМЫ КРЫМА
}

\author{
Ф.С. Ульмасвай ${ }^{1}$, И.В. Лазарева ${ }^{2}$, С.А.Добрынина ${ }^{1}$ \\ 1 - Институт проблем нефти и газа РАН, 2 - Центральный научно-исследовательский \\ и проектный институт по градостроительству Минстроя России \\ (ЦНИИП Минстроя России), e-mail: ulmasvai@mail.ru
}

Площадь Крымского полуострова - около 26 тыс. кв. км. Расстояние от Перекопского перешейка на севере до мыса Сарыч, самой южной точки Крыма, составляет 195 км, в широтном направлении от мыса Тарханкут до восточной оконечности Керченского полуострова 325 км. На сравнительно небольшой территории Крыма встречается огромное разнообразие форм рельефа, почв, растительного и животного мира.

Поверхность Крыма резко разделяется на северную, равнинную часть, занимающую примерно три четверти площади полуострова, и южную, горную часть. Рельеф равнинной части однообразный: на севере - это совершенно плоская равнина. Крымские горы протянулись вдоль Южного берега полуострова пологой дугой, длиной более 160 км и шириной до 40-50 км. Они четко разделены на три гряды: Главную, Внутреннюю и Внешнюю. Главная гряда протягивается от Балаклавы до Феодосии. Вершины ее представляют собой выравненные поверхности, в одних местах - широкие (до 8 км), в других - узкие, прерываемые глубоко врезанными верховьями рек. Исключительное значение в геологической истории Крымских гор и Скифской платформы принадлежит линейному элементу рельефа - линеаменту I-I (Приложение, рис.1). Он протягивается в меридиональном направлении от Алушты до Перекопского перешейка через Симферополь.

В геологическом строении Крымского полуострова выделяется несколько крупных структур различного возраста. Северная, Присивашская область Крыма представляет собой наиболее глубокую часть Причерноморской платформенной впадины (Каркинитско-Генический прогиб). Южнее расположено Симферопольское поднятие (Приложение, рис. 1), погребенное под мезо-кайнозойскими отложениями (Скифская плита). Между этим поднятием и структурами Горного Крыма расположена Альминская впадина, открытая на западе в Черное море. Впадина заполнена меловыми и палеогеннеогеновыми отложениями, залегающими на дислоцированных породах средней юры. Восточная часть Крымского полуострова представлена Азово-Кубанским прогибом, 
протягивающимся из Предкавказья [1]. Сивашская впадина является заключительной стадией развития передового Азово-Кубанского прогиба.

Первичные следы заселенности полуострова Крым уходят в глубь веков, не менее чем на 100 тысяч лет. Надежные письменные свидетельства освоения Крыма имеют возраст 3,5-4 тысячи лет. С того времени через Крым прокатилось несколько волн переселения народов. В разное время на полуострове жили и господствовали киммерийцы ( XII в. до н.э.), тавры ( VI в. до н.э.), сарматы ( I в. н.э.), скифы ( VII в. до н.э.), греки ( VII-VI в. до н.э.), аланы ( III в. н.э.), гунны ( I в. н.э.), евреи ( I в. н.э.), хазары (конец VII в.), половцы (XI в.), печенеги (середина X в.), армяне ( XIII в. н.э.), татары (XV в.), немцы (начало XIX в.), русские и украинцы ( XVIII в) и другие народы $[2,3]$. Каждая из народностей выбирала место жительства в соответствии со своим укладом жизни: кочевым или оседлым. От многочисленных племен и народов, сменяющих друг друга на Крымском полуострове, остались следы в виде археологических памятников, поселений различного масштаба. Одни поселения были «заброшены» следующими волнами переселенцев, а другие (Симферополь, Феодосия, Судак, Евпатория и т.д.) - в той или иной мере сохранились по настоящее время.

Проблема изучения взаимосвязи между природными особенностями территории, выбором места жительства и продолжительностью существования урбогеосистемы (урбогеосистема - система взаимобусловленных компонентов природной среды и селитебных территорий) [4-7] представляет как общенаучное, так и прикладное значение.

Среди важнейших условий выбора мест для проживания в древности было наличие питьевой воды и дорог, которые играли важную роль в коммуникации отдельных родов и племен, в потребностях производственной деятельности, в целях обороны и налаживания взаимоотношений с соседями. Эти два условия для формирования селитебных территорий тесно связаны с сетью линеаментов.

Для достижения поставленной цели проведен анализ густоты преимущественного простирания линеаментов, построены цифровые карты высот рельефа (рис. 2), преимущественного простирания линеаментов, плотности линейных элементов рельефа, рассчитаны роза-диаграммы простирания линеаментов по всей территории Крыма и отклонение их на локальных участках исследуемой территории от общей розыдиаграммы. В целом для всей территории Крымского полуострова распространение линеаментов по сторонам света показано на рис. 1. На картах преимущественного 
простирания и плотности линеаментов, а также по другим данным территория полуострова четко делится на ряд блоков (рис. 1). Сравнивая картины трещиноватости блоков с аналогичными картинами, полученными экспериментально [8-10], можно определить локальную геодинамическую характеристику блоков - преобладание локальных растягивающих и сжимающих усилий.

Первичные материалы для анализа заселенности полуострова Крым получены с карт Европейской части России из Атласа Маркса 1910 г. издания [11] и с топографического планшета L-36-Г (масштаб 1: 500 000, 1986 г., // http://www. loadmap.net/ru). По этим данным составлены две схемы расположения сел, станиц, поселков и городов: первая - показывает заселенность полуострова в конце XIX-го в., вторая - заселенность Крыма в середине XX-го в. (рис. 3 а, б). При проведении расчетов вся территория полуострова была покрыта сетью квадратных ячеек с шагом 10 км в масштабе карты. Рассчитана плотность населенных пунктов для каждой из вышеназванных схем. Распределение плотности населенных пунктов (на конец XIX в.) является четко выраженным логнормальным распределением, что позволяет говорить о малом числе факторов, влияющих на расселение людей в конце XIX в. В то же время аналогичное распределение плотности поселений (середина XX-го в.) имеет классический нормальный характер, отражает более значительное число факторов, влияющих на выбор места жительства (рис. 4). Для каждой из вышеназванных схем определены участки максимальной плотности поселений (рис. 5). В целом такие территории оказались практически одними и теми же для обоих рассматриваемых временных рубежей, в конце XIX в. они располагались на побережье или на незначительном удалении от берега моря, аналогичные участки с максимальной плотностью поселений в середине XX-го в. размещаются уже на несколько большем удалении от берега. При сопоставлении карт максимальной плотности населенных пунктов с картой морфоструктурного районирования п-ова Крым (рис. 5) оказалось, что участки с максимальной плотностью поселений расположены вблизи мест сопряжения тектонических блоков.

Проведенное исследование также показало, что предпочтения людей достаточно стабильны и меняется лишь небольшое число факторов, под влиянием которых с течением времени люди выбирают новые места для расселения. 


\section{ЛИТЕРАТУРА}

1. Летавин А.И., Орел В.Е., Чернышев С.М. и др. Тектоника и нефтегазоносность Северного Кавказа. М.: Наука, 1987. 94 с.

2. От киммерийцев до крымчаков (народы Крыма с древнейших времен до конца XVIII века) / Под ред. И.Н. Храпунова, А.Г. Герцена. Симферополь: изд-во «Доля», 2004. $288 \mathrm{c}$.

3. История Крыма // РБК daily, № 45 (1820) от 17 марта 2014 г.

4. Лазарева И.В., Лазарев В.В. Глоссарий: Градостроительные меры по предотвращению чрезвычайных ситуаций как ситуаций риска (RS). М.: ЛЕНАНД, 2007. $112 \mathrm{c}$.

5. Лазарев В.В. Национальное пространство. М.: Ассоциация строительных вузов, 2008. 544 c.

6. Ульмасвай Ф.С., Добрынина С.А. Геоморфологический модулятор княжеского выбора столиц // Градостроительство. 2014. №2(30). С. 82-85.

7. Ульмасвай Ф.С., Добрынина С.А. Краткий анализ связи географии городов с тектоникой в районе Левантийского разлома //Градостроительство. 2014. № 4(32). C. 58-61.

8. Шерман С.И., Семинский К.Ж., Борняков С.А. и др. Разломообразование в литосфере. Зоны сдвига / Отв. ред. Н.А. Логачев. Новосибирск: Наука, Сиб. отдние, 1991. 222 c.

9. Шерман С.И., Семинский К.Ж., Борняков С.А. и др. Разломообразование в литосфере. Зоны растяжения / Отв. ред. Н.А. Логачев. Новосибирск: Наука, Сиб. отд-ние, 1992. 256 с.

10. Шерман С.И., Семинский К.Ж., Борняков С.А. и др. Разломообразование в литосфере. Зоны сжатия / Отв. ред. Н.А. Логачев. Новосибирск: Наука, Сиб. отдние, 1994. 257 с.

11. Большой всемирный настольный атлас Маркса / Под ред. Э.Ю. Петри, Ю.М. Шокольского. Санкт-Петербург, 1910 г. (Режим доступа - www.etomesto.ru/ mapatlas_marksa. Атлас Маркса, онлайн. Карта Европейской России). 


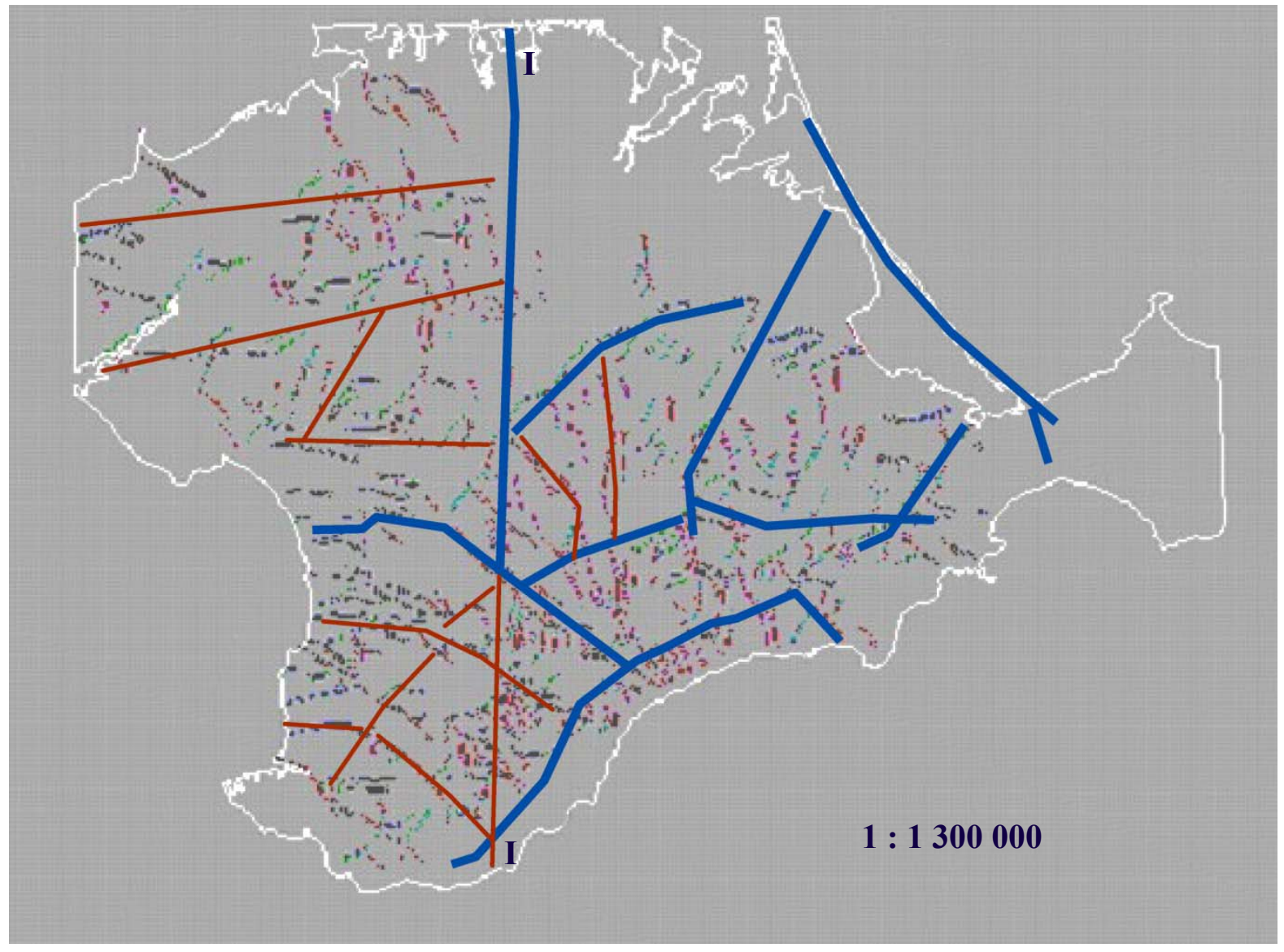

Рис. 1. Карта линейных элементов (линеаментов) рельефа, диагностирующих основные тектонические блоки полуострова Крым

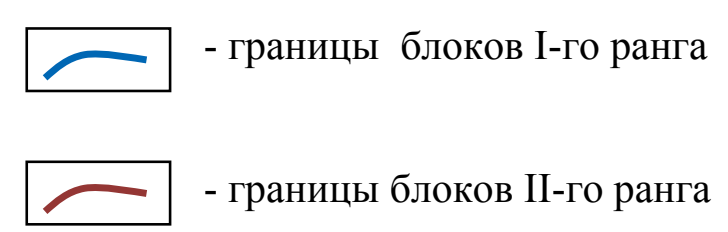






Рис. 2. Цифровая модель полуострова Крым

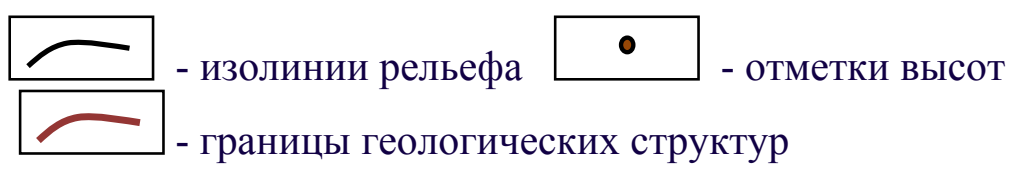


A

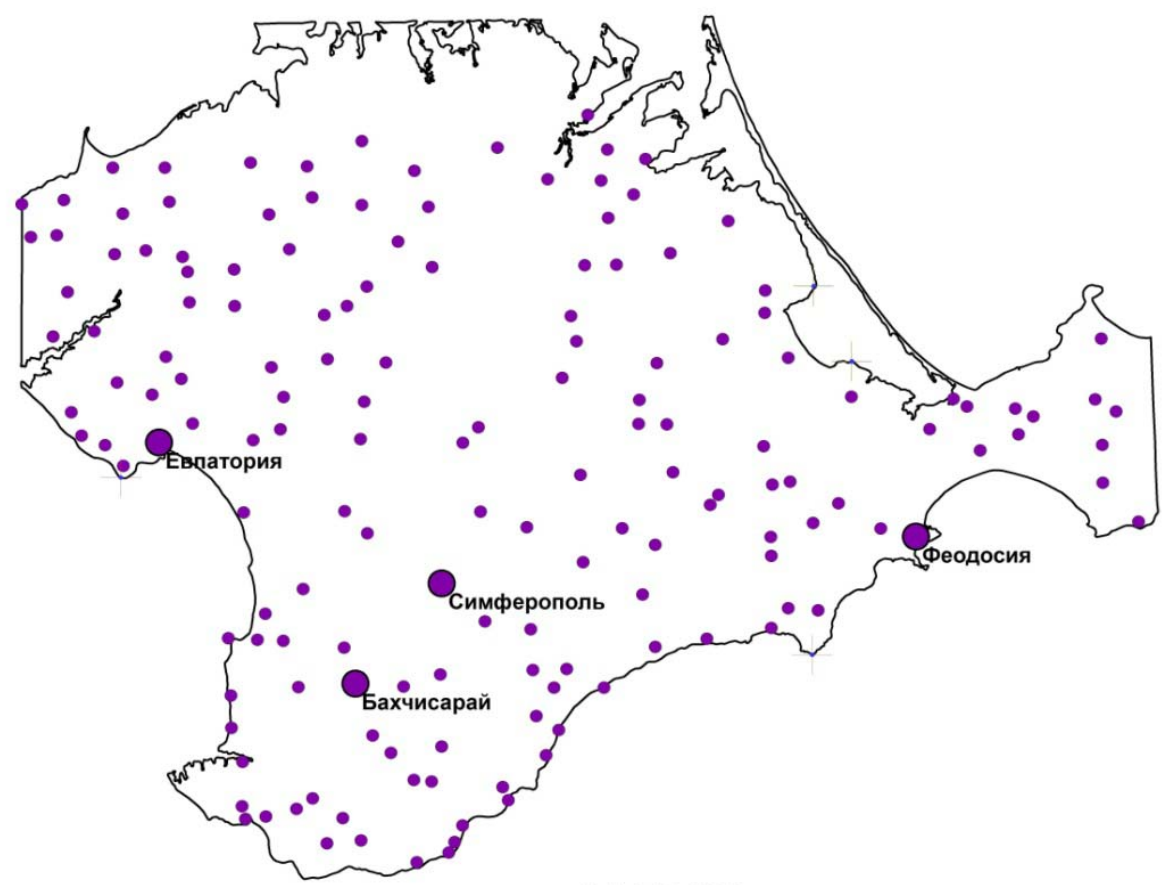

1:1300000

Н Населенные пункты

Б

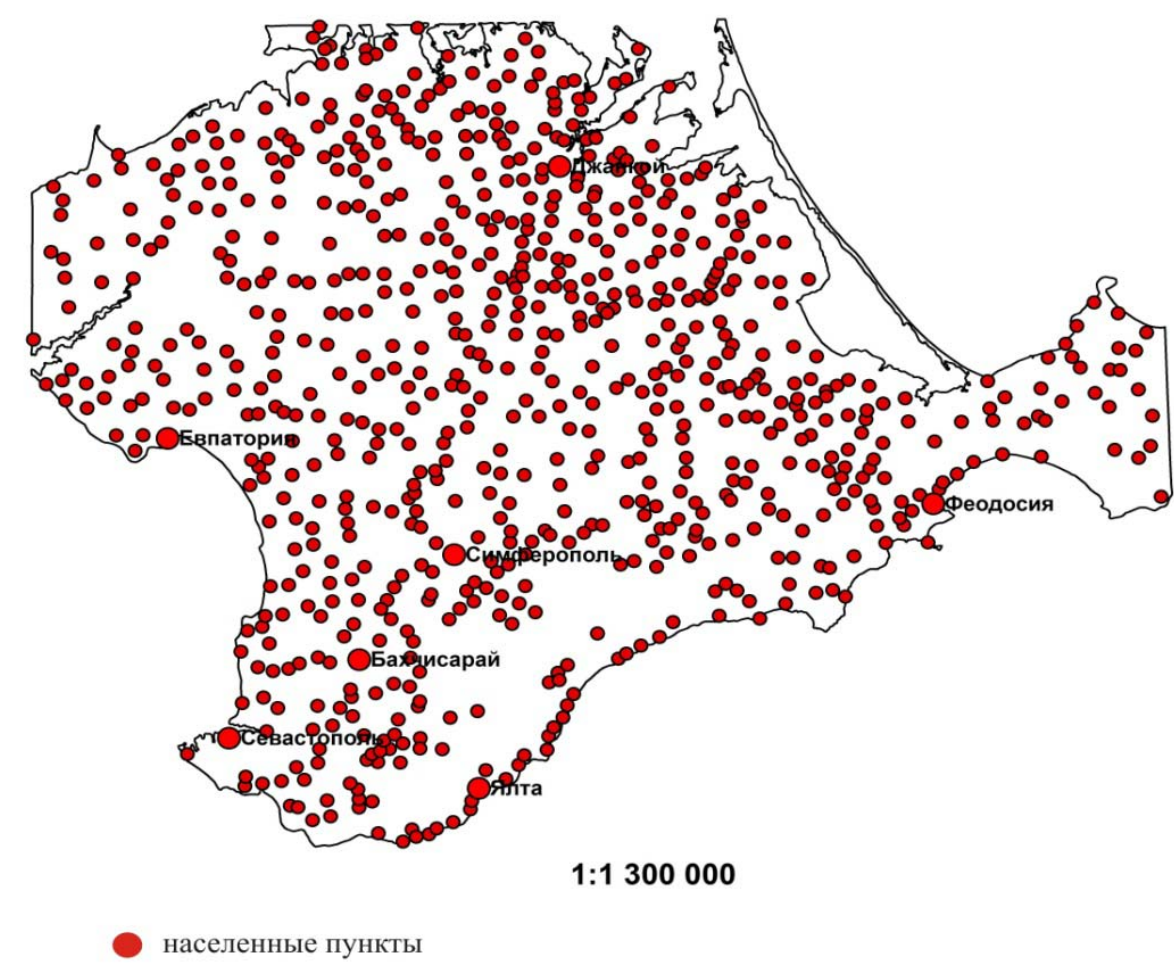

Рис. 3. Схемы расположения населенных пунктов полуострова Крым: А - заселенность Крыма в конце XIX в.; Б - заселенность Крыма в середине XX в. 

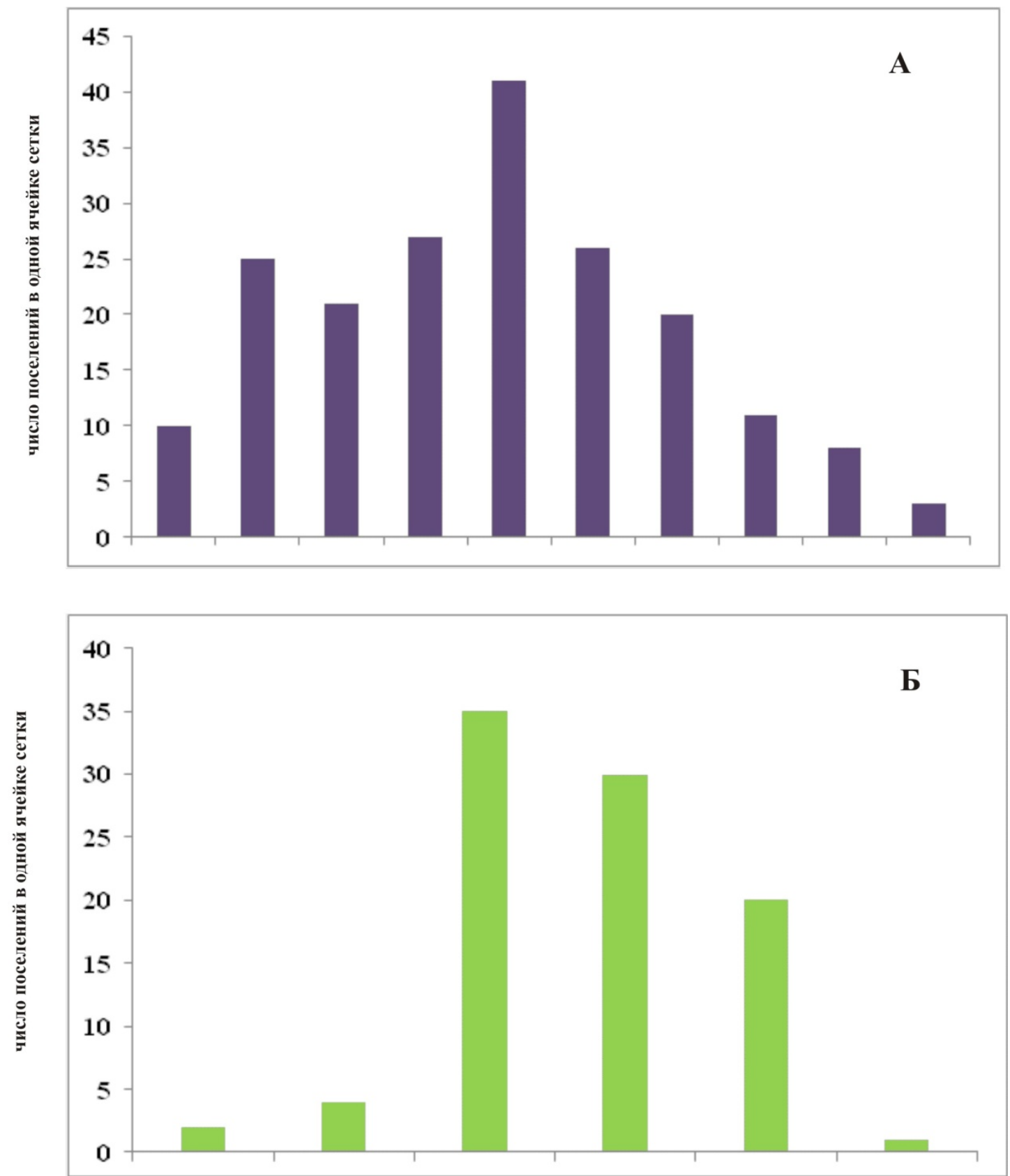

Рис. 4. Распределение плотности населенных пунктов: А - в середине XX в., Б - в конце XIX в. 




Рис. 5. Схема участков с максимальной плотностью поселений

Участки с максимальной плотностью поселений



- в конце XIX века

- в середине XX века

- границы блоков I-го ранга

-границы блоков II-го ранга 